\title{
La columna en verso: recuerdo y presencia de poetas y versificadores
}

\section{Journalistic Column Wrote in Verse: Memory and Presence of Poets and Versifiers}

Juan Cantavella. Universidad CEU San Pablo

Recibido: 24-I-2011 - Aceptado: 3-III-2011

Resumen:

A veces, entre la uniformidad de las columnas periodísticas, surgen formas singulares que tienen sus cultivadores y sus seguidores. Ocurre con la columna en verso, de la que encontramos muestras en el siglo XIX (Eduardo Marquina, José del Río Sáinz, Salvador M. Granés, Manuel del Palacio...) y en el XX (Luis de Tapia, Raimundo de los Reyes, Félix Antonio González, Jaime Campmany, Alfonso Ussía...). Aquí repasamos la historia de esta modalidad opinativa y las peculiaridades que estos autores aportan (sátira, humor y amenidad).

Palabras clave:

Columna periodística. Poesía. Sátira. Humor. Jaime Campmany. Alfonso Ussía.

Abstract:

Sometimes inside the uniform composition of journalistic columns emerge singular styles with its writers and followers. That's the case of column wrote in verse from XIX Century (Eduardo Marquina, José del Río Sáinz, Salvador M. Granés, Manuel del Palacio...) and the next one (Luis de Tapia, Raimundo de los Reyes, Félix Antonio González, Jaime Campmany, Alfonso Ussía...). This paper will examine the history of this opiner text and the peculiarities made by the mentioned authors (Satire, Humour and Amenity).

Keywords:

Journalistic Column, Poetry, Satire, Humour, Jaime Campmany, Alfonso Ussía. 
La existencia abundante y un tanto uniforme de columnas en todo tipo de periódicos nos puede hacer pensar que esta es una clase de textos exclusivamente de nuestros días y que las formas bajo las que se presenta se reducen a las que todos conocemos. Pero eso es ignorar la larga tradición que la acompaña y la singularidad de sus manifestaciones, algunas verdaderamente curiosas y dignas de ser atendidas. Hay que tener en cuenta además que, si bien algunas son minoritarias, no por ello han sido anuladas por completo de los medios impresos de nuestro tiempo. Aunque sea en contadas ocasiones, es posible apreciar muestras actuales en el cultivo de formas singulares, que en unas ocasiones presentan signos de ranciedad mientras que en otras están dotadas de potente lozanía. En cualquier caso merece la pena recordar su uso y dejar constancia de la corriente que representan.

En los análisis descriptivos de las formas de columna, en las taxonomías que algunos autores establecen, sobre todo si son exhaustivas, no se olvidan de ciertas presentaciones menos usuales y entre ellas nos encontramos con la que se apoya en el verso. Lo vemos en el manual de Fraser Bond: "El periódico que usa la prosa como su principal medio de expresión siempre cuenta por allí con algún espacio para la poesía (...). La columna de versos común y corriente consiste en un solo poema; algunas, empero, presentan varias piezas breves de diferentes autores" (1969: 277). Así es y, sobre todo, así fue en el pasado. Es fácil observar que los versos tienen en todos los tiempos un público adicto, aunque nunca mayoritario ni homogéneo, porque también cambian los tipos de poesía y la inclinación de los lectores por una u otra.

La divulgación de conocimientos, expresión de ideas, ataques a los adversarios y expansión de la intimidad, que algunos buscan reflejar en sus artículos, ya se hacían presentes con frecuencia en un tipo de colaboración periodística muy al gusto de nuestros antecesores del siglo XIX: la que se desenvolvía por medio de los versos. Había muchos poetas en todos los medios (varones, pero también mujeres en gran número), que aspiraban a que sus composiciones llegaran a los lectores de las hojas periódicas. Su presencia era sobresaliente y su calidad, en la mayoría de los casos, más que dudosa, pero ello no arredraba a los aspirantes ni por causas muy diversas se negaban los directores a publicarlas. Poco a poco se fue dirimiendo el valor de las aportaciones y de esa manera se apartó a los colaboradores espontáneos (más bien de escasa inspiración y destreza) de aquellos que terminaron quedándose en sus páginas, los que obtuvieron a cambio un espacio fijo y una periodicidad conocida, o sea, lo que hoy entendemos por columna. Se dejaron de lado los poemas de carácter íntimo o solemne, las elegías románticas, los sonetos piadosos, el romance épico y los himnos patrióticos. Entraron en su lugar la sátira, el epigrama, las coplas costumbristas y las que describen un tanto ripiosamente la actualidad. Bien podemos observar que no se trata mayormente de productos de calidad excelsa, sino versos de circunstancias, algunos más logrados que otros, por lo general muy intencionados y mordaces, hasta agresivos y sarcásticos en ocasiones. 
Muchas publicaciones de los siglos XVIII y XIX contaron con las aportaciones de estos cantores de sentimientos, que fueron bien recibidos por los lectores hasta alcanzar un gran reconocimiento. Mariano José de Larra, Gustavo Adolfo Bécquer, José de Espronceda, Gaspar Núñez de Arce, Manuel Bretón de los Herreros, José Zorrilla y Manuel del Palacio fueron mucho más que eso, porque sus libros dan idea de la calidad que imbuían a sus versos. Al mismo tiempo muchos otros de inferior calidad se dieron a conocer en la prensa española y de los países hispanos, en la que ocuparon puestos destacados y, si bien ciertos nombres no pasarán a la historia de la literatura, no tenemos que ningunearlos en la del periodismo. Casi todos ellos gozaron de enorme popularidad, tanto entre las gentes ilustradas como entre las sencillas.

Hay que distinguir la publicación esporádica de versos de la configuración de secciones que toman esta forma por su valor satírico, humorístico o que comentan la actualidad desde su personal punto de vista. Ambas vertientes se han dado con frecuencia en los siglos pasados, sobre todo la primera, aunque a medida que avanzaba la pasada centuria se restringían estas expansiones, que indudablemente tenían su público, pero que ya iban siendo contempladas como manifestaciones un tanto obsoletas que nada decían en un contexto moderno donde impera la información y el debate argumentado. Ocurría en los periódicos españoles, pero también en las naciones hispanas, y para reflejarlo en este trabajo, hemos seleccionado algunos ejemplos de la prensa peruana.

Pocos eran los diarios y revistas que en el siglo XIX se libraban del asedio a que los sometían los poetas, aunque mejor estaría hablar de versificadores (porque eran los que más abundaban). Al abrir cualquier periódico nos podríamos encontrar con muestras del ingenio y de la creatividad, pero regularmente también de la ramplonería y del prosaísmo, de quienes habían elegido la poesía como forma de expresión y consideraban que los medios impresos eran un cauce apropiado para darle curso. En otras ocasiones era la sátira política la que tomaba un vuelo considerable y eso no gustaba a los que ostentaban el poder, hasta el punto de que el real decreto sobre libertad de imprenta que firma Javier de Burgos en 1834 (durante la regencia de María Cristina de Borbón), después de hacer referencia a las novelas y piezas dramáticas, "advierte también que sobre todo hay que cuidar de la poesía, pues 'los versos se imprimen fácilmente en la memoria, y son capaces de difundir el desprecio hacia las personas y las cosas más respetables'” (Zavala, 1972: 46). Es que por entonces los temas patrióticos se barajan con las letrillas picantes: unas y otras despertaban enorme pasión y eran motivo de lecturas complacidas y hasta había quien se las aprendía de memoria. Por ejemplo, el primer número de El Juicio Nacional (Lima, 25 de enero de 1836) se inicia con un soneto vibrante que es un reconocimiento de la libertad y un rechazo de la opresión: 
"Alza tu cuello pueblo afortunado

De las cadenas hórridas que un día

Lanzara en su furor la tiranía

Para oprimir tu suelo malhadado...”

En otras ocasiones lo que imperaba era la sátira y en la prensa peruana del pasado abundan las cabeceras que, además de las prosas chispeantes, incluyen versos que pretenden provocar risas a costa de algunos conciudadanos, esos a los que por sus defectos personales o actuaciones que se consideran desafortunadas se les hace objeto de chanzas, a veces casi sangrientas. Basta citar los nombres de Joaquín de Larriva (1780-1832) y de Felipe Pardo y Aliaga (1806-1868), que intercambiaron pullas y mofas, de la misma manera que en períodos sucesivos podríamos encontrar otros escritores-periodistas, bien dotados para semejante juego, por lo general muy grato para el público.

\section{Comienzos de una tendencia}

Algo semejante hallamos en la prensa española, con una abundancia igual o superior de versos que tocan toda clase de temas y líneas de expresión. Como mera curiosidad podemos aportar los versos con que saluda su aparición El Duende crítico de Madrid (8 de diciembre de 1735), primer periódico que se sitúa en la línea satírica que tantos continuadores tendrá en los siglos siguientes, en esta ocasión escondida la autoría para evitar las represalias (pero de las que no se verá libre su autor, fray Manuel de San José):

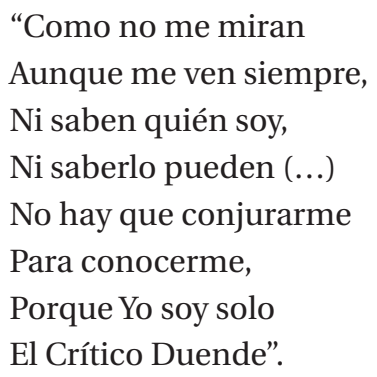

O la declaración de intenciones (tal vez equiparable a un editorial) con que se presentaba el Diario de Barcelona el 1 de octubre de 1762. Eran las palabras que el editor dedicaba a los ciudadanos en su primera salida a la calle y estaban escritas en verso:

"Si merezco tu agrado

Bajo tu sombra crecerá el desvelo, 
Con que entraré tal vez en paralelo,

De tanto ingenio al Mundo dedicado

Tendrás útil recreo consagrado

A tu literatura.

Ojalá a tu lectura

Baste la débil luz de mi talento:

Este es el fin de mi sincero intento".

Pero a lo que deseamos referirnos aquí es a la calidad de columna que tienen algunas de estas colaboraciones, asentadas como sección fija en las páginas de ciertos periódicos. No es una presencia avasalladora, pero ha tenido su rincón en gran número de medios y, sobre todo, ha sido apreciada por los lectores. "Durante los últimos años del pasado siglo [se refiere al XIX] y los primeros del actual-escribe Sáinz de Robles-, estuvo muy en boga que en la prensa (...) se publicaran diariamente poesías satíricas o festivas dedicadas a comentar la actualidad, los sucesos 'con mucha miga'. Las malas costumbres de la sociedad, poniéndolas 'en solfa' e intentando... corregir sonriendo” (Reyes, 1958: 9).

En esta línea se sitúa Manuel del Palacio, que hemos citado antes, como podríamos aludir a Luis de Tapia, Raimundo de los Reyes, Jaime Campmany, Félix Antonio González y Alfonso Ussía, entre los muchos que nuestros periódicos acogieron (y aún se podría añadir los nombres o seudónimos de Gil Parrado (Antonio Palomero), Mingo Repulgo (Joaquín González Pastor), Carlos Miranda, Carlos Luis de Cuenca, Agustín R. Bonnat, Tartarín (Francisco Serrano Anguita), Juan Pérez Zúñiga o Francisco Ramos de Castro ${ }^{1}$... ; y aún Luís Rivera, Clarín (Leopoldo Alas), Sinesio Delgado, Vital Aza, Luis Taboada, José Selgas, Juan Martínez Villergas $^{2}$, Felipe Pérez y González, López Pinillos³...). Seguiremos la huella periodística de algunos de ellos, porque son ilustrativas de esta tendencia.

Pero antes de entrar en la exposición de las trayectorias de quienes más han destacado en este campo deberíamos escuchar a Gerardo Diego para quien “una página de la historia literaria que está, según creo, por

\footnotetext{
Sáinz de Robles aporta algunos de estos nombres y apostilla: "La diaria gracia satírica versificada de tales ingenios, mantenida durante años por cada uno de ellos con indudable fuerza aleccionadora, asombra y exige llevarla a la cuenta de cualquier historia de la poesía que se redacte con objetividad" (Cf. Reyes: 9). Una consideración tan entusiasta como escasamente admisible, porque algunos de ellos no son sino versificadores lúcidos y chispeantes, con más ingenio que genio.

2 Capaz de imprimir la marca de su humor en todas las colaboraciones periodísticas que emprendía, pero también en muchos momentos de su vida, aun los más aciagos. Cuenta Ossorio que el director de La España Moderna le pidió un texto para su revista cuando Villergas se hallaba muy enfermo y su negativa la envolvió con estas razones: "No puedo escribir nada; estoy ocupado en la tarea de morirme" (2004: 264).

3 Estos últimos señalados por Bernardino M. Hernando (2007: 131).
} 
escribir, sería la que estudiase esta fresca ramazón y floración de literatura en verso, si no queréis, por escrúpulo preceptivo, que la llamemos poesía”; material no faltaría, pues "a comienzos de nuestro siglo [el XX] no era raro en la Prensa española mantener una sección poética diaria, casi siempre en tono humorístico, satírico o festivo. En este tono se hicieron, como también en el siglo XIX, verdaderas filigranas" (1945: 1345).

Aduce dos ejemplos: el de Eduardo Marquina (1879-1946), cuyas Canciones del momento fueron publicadas por un diario de Madrid y después en un volumen prologado por Enrique Gómez Carrillo que lo alababa con estas palabras: "Cantar la llegada de Carolina Otero sin bromas, comentar los veredictos del Jurado sin bromas, celebrar la alianza anglo-rusa sin cuchufletas, defender a Dreyfus en estrofas iguales a las que otros emplean para decir amores ideales; eso sí que es singular!” Otro ejemplo sería el de José del Río Sáinz (18861964), quien recreaba acontecimientos relacionados con la primera guerra mundial, después recogidos en el libro La belleza y el dolor de la guerra. Aún podríamos añadir el nombre de Salvador M. Granés (18401911), director y redactor de varios periódicos y autor de unos "ripios punzantes", al decir de Fernández Almagro (Espina, 1960: 208), de los que apenas ha quedado huella.

\section{Manuel del Palacio y Luis de Tapia}

Pero vayamos a los más conocidos. Manuel del Palacio (1832-1906) se distinguió a lo largo de su vida por su vinculación con un número ingente de publicaciones, tantas que Osorio relaciona casi una treintena de títulos y aún añade que sus colaboraciones aparecieron en "cuantos periódicos de alguna importancia se han publicado durante los últimos cuarenta años” (2004: 325). Entre ellos destacan los de carácter humorístico, a los que aportaba, con los versos, el furor de sus picaduras. Cuando enfilaba el aguijón contra alguien lo podía dejar temblando por el veneno que destilaba. Y si no que lo diga un ministro de Estado, Juan Manuel Sánchez y Gutiérrez de Castro, duque de Almodóvar (de condición noble y título de Grande de España, aunque de escasa estatura), que a la vista de que nuestro personaje cobraba en sus oficinas, pero no acudía regularmente a desempeñar trabajo alguno, optó por desposeerle de su condición de funcionario. Con la siguiente quintilla le dejó señalado para siempre:

"Dice que es Grande y es chico;

Fue Ministro porque sí,

Y en cuatro meses y pico

Perdió a Cuba, a Puerto Rico,

A Filipinas y... a mí" (Gómez Aparicio, vol. II: 187)4.

"El ataque fue certero y la venganza cumplida, pues aquel ministro incoloro que nadie recordaría hoy por su obra ministerial, perdura 
Clarín escribió que "Palacio fue muchos años un periodista en verso. Como otros escribían artículos de actualidad, él entregaba al confeccionador del periódico versos de actualidad, sonetos, muchos sonetos, quintillas, romances, tercetos, etcétera, etcétera” (Clarín, 2004: 492). Mantuvo estas secciones en verso en diversos diarios y revistas, como la sección "Chispas” en El Imparcial, donde aparecía diariamente un soneto que comentaba la actualidad de manera sumamente crítica; en la sección "Zumbidos y picaduras”, de El Mosquito, y en el irreverente Gil Blas, donde publicó unas “Caricaturas revolucionarias”: retratos intencionados y punzantes que aparecían acompañados de dibujos que participaban de ese aire deformante y malévolo que querían infundirles. A quien elegía para glosar su figura o sus acciones lo dejaba destripado sin remedio. Véase lo que escribía sobre el general Prim, el que trajo a España una revolución y luego tuvo que buscar por doquier un rey que remediara aquella orfandad a la que nuestro pueblo no se hallaba acostumbrado:

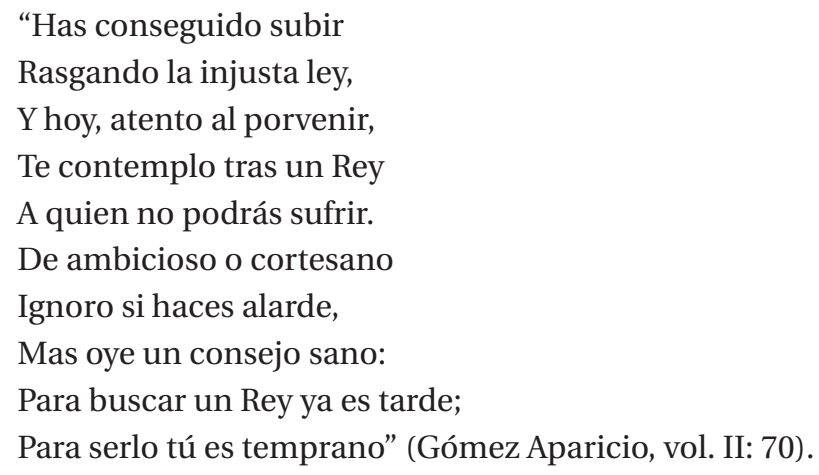

Luis de Tapia (1871-1938) se encontraba en parecida onda y participaba con sus versos en todas aquellas revistas satíricas que apreciaban el tono zumbón y pícaro de que hacía gala. Pero también diarios serios, como era $A b c$, tenían secciones de este carácter. Una de ellas era su "Gacetilla rimada", que no estaba a cargo de un solo colaborador, sino que era compartida por unos cuantos periodistas, amigos de la chanza (con frecuencia política): Sinesio Delgado, Juan Pérez Zúñiga y Luis de Tapia. En el diario España Nueva (desde 1906) participaron una serie de autores jóvenes, como Tapia, “autor de los pronto afamados ‘Bombones y caramelos', escritos en un verso ripioso y facilón, pero extraordinariamente eficaces por su intención política”. Y en la Revista Nueva, en colaboración con el caricaturista Manuel Tovar, "publicaba semanalmente unas desenfadadas aleluyas, anticipación de las 'Coplas del día' que no mucho después habría de inaugurar en las páginas de La Libertad”, según Gómez Aparicio (vol. III: 287 y 530). Este alude más adelante a esta

cómicamente en nuestra memoria por el ingenioso epigrama de Manuel del Palacio” (Espina, 1960: 174). 
sección y se refiere a las "ripiosas, aunque siempre cáusticas e ingeniosas" coplas. En todas ellas se distinguía por su capacidad de clavar el dardo sin ningún tipo de miramientos.

Sus colaboraciones en La Libertad fueron muy celebradas (se habla de que en este y otros medios fueron más de veinte mil las que escribió). Pérez Galdós prologó uno de sus libros y allí le calificaba de "poeta de inspiración risueña, de estilo picante y frescachón”. Obsérvese, como mera ilustración del tono que empleaba, cómo terminan las coplas que un día cualquiera dedica a un discurso de Antonio Maura:

“Otras mil frases oí

De Maura, y me sonreí...

Cuando ya se ha gobernado

Y, además, se ha fracasado,

No se puede hablar así.

(¡Digo, me parece a mí!) (Espina, 1960: 277).

Como también se hizo notar su carácter anticlerical y antimonárquico. Fue uno de los redactores del periódico El Evangelio, reciamente iconoclasta. Allí aparecieron sus secciones "Noticias en huelga" y "Salmos", estos firmados por "David". En tiempos de la II República sus versos tuvieron un aire marcadamente izquierdista y a la marcha del Rey dedicó unas coplas en la que mostraba su distanciamiento:

"Ya es triste cruzar España

Cuando es flor todo el país!

¡Cuando en fecundos olores

Florecen todas las flores

Menos las flores de lis!"

Haro Tecglen, quien le admiraba, cuenta de qué manera tuvo que abandonar Madrid en 1936 ante la presión de las tropas "nacionales” y refugiarse en Valencia (había sido diputado republicano), donde la depresión por lo que estaba sucediendo le atenazó de tal manera que falleció al poco tiempo: "Se salvó de todo lo de después. Le hubieran matado”, asegura Haro. Ser tan crítico no conduce a nada bueno, podríamos añadir a la vista de esta y otras dedicaciones.

\section{Dos secciones del diario $\mathrm{Ya}$}

No es extraño, por tanto, que tales furores se moderaran hasta extremos desconocidos por la tradición anterior cuando el franquismo impone la atonía y el grisor en la prensa, además de una rígida censura, por 
supuesto. Surgen entonces una serie de cultivadores de un verso anodino y afable, que no hiere a nadie. Mantiene una suave crítica social, de carácter genérico, para que ninguna persona ni grupo se pueda dar por aludido (naturalmente jamás se nombra a nadie si no es para ensalzarle). Se podía comprobar en el diario $Y a$, que durante muchos años contó con la colaboración poética diaria de Raimundo de los Reyes y después de Félix Antonio González.

En esa línea el diario recibió en los años cincuenta del pasado siglo las aportaciones rimadas del primero, que firmaba como Luis Romera, probablemente para que esta dedicación no entorpeciera los trabajos "serios" que publicaba en otras páginas ${ }^{5}$. Sus "Ripios del día” eran una especie de repaso amable de lo que sucedía, ya fueran glosas de la actualidad, comentarios livianos sobre la vida que se observa, como llamadas de atención ante conductas sociales inapropiadas (para él lo eran, dado el tiempo en que escribe, el que las mujeres llevaran pantalones o el que los novios caminaran cogidos del brazo).

Raimundo de los Reyes (1896-1964) era un poeta lírico que publicó varios libros de calidad a lo largo de su vida: sus versos rezuman los aires de su Murcia natal, en cuyo diario La Verdad trabajó hasta que en 1935 pasó al Ya de Madrid. Aquí desempeñó la secretaría de redacción y sus escritos llevaban una doble dirección: por una parte, la crónica madrileñista que aparecía con la firma de Hilarión y el título genérico de "El oso y el madroño" (a veces escrita en forma rimada, como después veremos que también practicó su paisano Jaime Campmany); y, por otra, los versos de actualidad (desde 1953 y hasta muy poco antes de su muerte) en el tono apuntado, con la facundia y bonhomía que siempre complace. Practicaba una especie de costumbrismo para dejar constancia de lo que sucede y de la añoranza por los valores que se iban perdiendo y, al mismo tiempo, se percibe la pretensión de corregir todo aquello que desde su perspectiva merece ser puesto en la picota. Su prologuista, Sainz de Robles, afirma que aspiraba a "intentar correcciones con palabras terminantes, pero melificadas por la comprensión, la piedad y la melancolía” (De los Reyes, 1958: 12). Aunque no suele ser un fustigador de maldades, sino cantor de sentimientos y de los hechos menudos que ofrece la actualidad, véanse estos versos que dedica a la corrupción:

"Se ha perdido una paloma

Con el buche atiborrado

De joyas. Esto no es broma,

Pues la prensa lo ha contado.

También para proteger su identidad: después de pasar en la cárcel los tres años de la guerra civil, mantuvo sus distancias respecto a la dictadura. 
El caso es cosa corriente,

Pues suele ocurrir al hombre

Lo mismo frecuentemente,

Y ello, lector, no te asombre.

Hay quien en su cargo pasa

De honradez por un estuche,

Y luego se va a su casa

Con un tesoro en el buche" (De los Reyes, 1958: 171).

Más pegado al suelo se nos representa Félix Antonio González, de quien recordamos un recuadro en las páginas finales del diario $\mathrm{Ya}$, entre las viñetas humorísticas y los pasatiempos. Cualquier tema era susceptible de ser abordado allí y lo hacía con el ingenio del punto de vista elegido y de la forma rimada con que lo recrea. Un ejemplo que podemos aportar (12-XII-1979, p. 44) está dedicado a un tema nimio, un reloj de cierto porte que alguien acaba de adquirir:

"En el Rastro, el otro día, una buena amiga mía compró un reloj de pared. Es un reloj, isabe usted?, dotado de sonería".

Pero parece que el servicio de ofrecer la hora lo realiza a bombo y platillo, hasta el extremo de que se hace notar demasiado:

"Los vecinos, todos, con fraternal preocupación, por todas partes llegaron y alarmados preguntaron si desplome o explosión. El reloj. Bonito y tal, de madera y de metal, y, ay madre, con sonería. Pero habría que ponerle un bozal".

Como se ve, es un comentario amable sobre lo que puede suceder en cualquier hogar, que se encuentra con un producto vistoso, pero que al instalarlo no calibran las consecuencias desasosegantes que puede re- 
portar. Félix Antonio González (1921-2009) fue un poeta de una cierta altura metido entre las prosas de los periódicos: no solamente porque escribiera versos de ocasión, sino porque así se sentía él. Fue director de un reputado diario de Valladolid, su ciudad natal, pero lo que más le gustaba era desperdigar sus composiciones cotidianas en otras muchas cabeceras y, para no contravenir aquello de la exclusividad, en cada uno de los periódicos en los que colaboraba lo hacía utilizando un seudónimo diferente (no menos de cinco, aunque el más conocido era Ansúrez). Alguna vez parece que se lamentaba de que aquella entrega al verso de circunstancias le había impedido alzar su vuelo con más altas ambiciones, pero tampoco fue así, ya que ganó destacados galardones y también era conocido en los ambientes más puramente poéticos. Pero era como una doble vida, que recataba en cada círculo aquello a lo que esas dos derivaciones de su afición le impulsaban.

Dirán que los temas elegidos por estos periodistas, que allí no pasaban de versificadores de postín, no picaban muy hondo, pero, ¿qué otra cosa podían hacer en un tiempo de censura irritante y de nula capacidad de aceptar crítica de ninguna clase y hasta de tolerar el humor, por descafeinado que apareciese? Los gobernantes podían aguantar alguna que otra broma, pero no la sátira que tanto imperó en la prensa anterior y que luego iba a volver; ni los epigramas que, imposibles de ser recogidos en letra impresa, circulaban oralmente, por tertulias de café y redacciones iconoclastas (todas lo son) (Campmany, 1996). Hubiera sido imposible recoger los feroces versos que un Pérez Creus, por ejemplo, prodigaba a todas horas y que solo tuvieron cabida en los semanarios Sábado Gráfico y Época (con los seudónimos de Maese Pérez y El Diablo Cojuelo) cuando la libertad de expresión se acercaba o se había instalado entre nosotros.

\section{Jaime Campmany}

Ese antes y después lo conoció bien el poeta del que nos ocuparemos a continuación, porque otro gran aficionado a la columna es Jaime Campmany, quien la practicó durante muchos años y hasta el mismo día de su muerte, fiel a esa adicción en que se convierte para muchos periodistas de raza el hacerse presentes ante los lectores sin faltar una sola jornada a su cita. Como todos los anteriores hacía gala de una enorme facilidad para versificar sobre asuntos de actualidad, pero también para dirigir sus dardos contra sus enemigos políticos o todos aquellos cuyas acciones les hicieran merecedores de las burlas que sabía prodigar. En este caso no se ocupa de cuestiones menudas y de palpitación cotidiana, sino de esas otras de mayor volumen referidas a los asuntos públicos de la nación. Cultivaba sobre todo la columna política desde una posición conservadora en la que militaba (al contrario del izquierdismo de Umbral o la actitud intermedia, un tanto 
escéptica, que es donde podríamos situar a Manuel Alcántara6), porque un escritor que cada día tiene que manifestar su pensamiento es difícil que pueda ocultar su ideología. Eso solo lo pueden sostener los mudos, no los que hablan a borbotones.

La columna en sus manos ha tenido varias manifestaciones y. si tuviéramos que señalar dos épocas notables de esta dedicación (porque alguna más hay), tendríamos que referirnos a las que protagonizó su "Pajarita de papel" en el diario Arriba en los años ingratos del franquismo y la que ha estado cultivando en el diario $A b c$ para deleite de los lectores, tal vez de la misma filiación, pero ya adaptados a la democracia. Dos épocas y dos estilos, pero una misma fidelidad a un género, que en su caso se desprende de la enorme afición que ha sentido por el artículo, al que ha estado permanentemente prendido, ya desde sus años mozos.

Esa "Pajarita de papel” venía acompañada por un dibujo que la representaba y que era su seña de identidad. La depositó en el sector de la prensa más ligada al sistema franquista (a la que sirvió durante muchos años), pero su autor le tenía mucho cariño, "porque creo que logré decir muchas de las cosas que en aquel tiempo estaban prohibidas, gracias a usar un tono de humilde intimismo y hasta de reproche lírico que me proporcionaron un cierto éxito" (1997 a: 21). Su existencia se prolongó durante unos cuatro años de forma continua (mientras fue director de una agencia oficial, de 1966 a 1970) y algún tiempo más de manera discontinua (lo que constituye un tipo de columna atípica), pero las presiones políticas que estaba recibiendo le impulsaron a buscar la retirada, porque dice que no era cuestión de aceptar mandatos y prohibiciones. Era a finales de los años sesenta, cuando se estaba produciendo una cierta liberalización del régimen, tendencia que Campmany aseguraba defender, pero se dio cuenta en un momento determinado de que encontraba demasiadas dificultades para llevar a cabo lo que quería, a causa del ambiente cerrado en el que se desarrollaba su trabajo, y eso no era bueno para la columna.

Muy diferentes fueron los años posteriores, en que fue captado por $A b c$ y estuvo manteniendo una sección fija de carácter político, sus “Escenas políticas”. En ella se posicionó de una manera inequívoca en defensa de las ideas derechistas, pero lo que aquí nos importa es la traza con que se expresaba, porque estamos refiriéndonos a los continentes, no a los contenidos. Y esa traza era de una calidad sobresaliente, tal vez porque llevaba muchas décadas dedicado a este menester y dominaba las artes de dar en la diana y obtener la be-

6 Gregorio Salvador contrapone precisamente el hecho de que buena parte de nuestros comentaristas "entran al trapo ideológico siempre que pueden y dan preferencia al suceso político sobre cualquier otro tema de actualidad” a la aportación de Alcántara, “que prefiere otra clase de asuntos y que pone siempre una cierta distancia, por elevación, sobre los hechos que comenta y solo toma partido cuando no hay más remedio que tomarlo, porque hay cosas sobre las que no cabe entretenerse en la duda" (Ateneo del Nuevo Siglo. Número monográfico dedicado a Manuel Alcántara. Málaga, 2005, p. 91). 
nevolencia del público. Más que razonamientos argumentados, lo que prodigaba en este espacio eran ataques directos a los adversarios, a base de poner de relieve los errores ajenos, los vicios descubiertos, la ridiculización de los comportamientos observados, las cuchufletas sobre todo aquello que consideraba risible y, sobre todo, la caricaturización de los personajes.

Un buen día descubrió el excelente juego que podría dar el verso aplicado a las cuestiones políticas y como sustituto de la prosa con que siempre se ofrece la columna en los periódicos. Es más, la rima podía desempeñar el papel de propagador de los conceptos y dinamizador de esa influencia que buscaba a través de sus escritos. La recepción positiva que se obtiene de los lectores se acentúa de forma muy destacada cuando un escrito se presenta de esta manera tan original y poco frecuente. El público aprecia de forma inmediata el ingenio que se derrocha y la habilidad de juntar ideas y asonancias.

Cúmplenos advertir que Jaime Campmany es un poeta de gran sensibilidad, con una serie de obras publicadas en este campo desde su juventud. Ha leído y escrito mucho, con una honda preparación para acercarse a los clásicos y digerir sus propuestas, recordar las ideas más certeras y dominar las diferentes expresiones de la métrica. No cabe duda de que su disposición para abordar una forma tan sencilla como el romance es formidable y eso se nota en los resultados. Los versos le salen con rapidez y soltura, algo que le beneficia a él, pero que también repercute en el agrado con que son recibidos.

A su juicio, la cantinela del romance prende muy bien en el oído de los hablantes de la lengua española. Esos octosílabos con rima asonante, en el que casan los versos pares y se dejan libres los impares (que es el sistema habitual, aunque haya algunas variantes), nos llegan después de una tradición secular, por lo que son fáciles para quien los compone ("El verso de ocho sílabas mana en castellano sin necesidad de medirlo", afirma este autor, 1997a: 20) y prenden con agrado en quienes los escuchan. Jiménez Losantos explica que en nuestra cultura se ha producido un culto al verso largo, cuya cima es el endecasílabo, pero también al tradicional, que está representado por el octosílabo del romance. Y si primero los grandes poetas cultivaron aquel, que les parecía sublime, después se ha producido una fuerte atracción por el octosílabo por dos razones: "Por el valor literario del Romancero, que guarda algunos de los hallazgos líricos más felices de nuestra historia literaria, y porque, técnicamente [es] el verso que quizá se ajusta mejor a la cadencia de nuestra lengua” (1994: 12). En su aplicación a los textos periodísticos es el más apropiado, ya que el articulista no se encuentra tan cómodo con otros metros.

Entrar en este terreno fue algo casual, nada premeditado. Un día se puso a jugar con el encadenamiento de versos y en apenas un rato vio completado el poema, porque percibía que las series salían ellas solas, como si se deslizaran sobre el papel sin esfuerzo alguno. Así lo recordaba con posterioridad, pero con un aña- 
dido: cuando concluyó de dictar aquella columna tan especial, el taquígrafo que la estaba anotando le aplaudió y, al ser publicada en el diario $A b c$ tuvo una inesperada repercusión en forma de llamadas y cartas de lectores que se habían quedado prendados de aquella novedad, que la consideraban atractiva. De hecho, entre otras consecuencias, ha contribuido a popularizar esta forma métrica y ha logrado que otros columnistas le imitaran y jugaran con ella.

Inauguró esta aportación con su "Romance de ciegos": el título hace referencia a los cantos de los juglares, muchos de los cuales estaban privados de la visión y por ello tenían que ganarse la vida de esta manera; así prodigaban sus habilidades por las plazas de pueblos y ciudades españoles en los tiempos medievales. El romance constituía el instrumento con el que se divulgaban los acontecimientos de toda índole. Imitar aquella tradición resultará bien significativo de la línea por la que iban a discurrir sus colaboraciones posteriores, las que ya nunca dejaría por el impacto y el provecho que le reportaron:

"Campesinos de esta tierra, / buenas gentes de este pueblo, venid a oír el romance / que canta este pobre ciego. Óiganle los menestrales, / hacendados, jornaleros, matasanos, boticarios, / justicias y picapleitos. Escúchenle curtidores, / rapabarbas, carpinteros, sochantres, afiladores, / alguaciles y maestros; capadores, trujimanes, / prestamistas, bodegueros, feriantes y matarifes, / recaudadores de impuestos, espadones y bonetes, / chupatintas y carteros, destripaterrones, cómicos. / Sastres y picapedreros; lazarillos, asesores, / adlátares de consejo, secretarios, raboalcaldes / y demás mamandurrieros..." (1995: 17).

Pronto se dieron cuenta algunos directores de programas en una cadena radiofónica que esta habilidad podía tener un feliz aprovechamiento en la radio; que si estaba bien lo que escribía para las páginas de un diario, mejor podría resultar si lo leyera de viva voz ante los micrófonos; que a la letra de aquellas cuestiones actuales, con una clara inclinación hacia los problemas políticos, le vendría de perlas la música que se desprende del romance. Y en 1992 comenzó a declamar sus versos en la cadena Cope, también con una inusitada aceptación por parte de los oyentes.

Una de las cualidades más apreciables de su prosa en todos los tiempos era la riqueza léxica de que presumía, capaz de realizar un despliegue espectacular de palabras a propósito de cualquier materia o situación. Entonces sacaba a relucir los términos numerosos y jugosos que almacenaba en su mente, tanto prove- 
nientes del español culto como del coloquial, de las jergas y de los dialectos. Se notaba que había leído a los clásicos y que conservaba de aquellas lecturas tempranas y constantes la memoria de unas palabras que con suma frecuencia los demás olvidamos al cabo de poco tiempo, si es que alguna vez las hemos aprendido.

Su dominio del vocabulario es algo que llama la atención de inmediato. Al decir de Jiménez Losantos, "nadie usa hoy uno más amplio, nadie exhibe más recursos de almacén y bodega que este diccionario ambulante, memorión prodigioso y erudito cuando quiere. En él sobresale una buena formación clásica y eso que Azaña echaba de menos en Ganivet: 'la solera de fuertes lecturas españolas'. En la cita es implacable; en la adjetivación, abrumador; en la sintaxis, impecable; en el ritmo, inagotable; en la pelea, agotador" (1994: 15). Para algunos será un defecto la facilidad de que hace gala en la composición, pero ojalá todos los profesionales tuvieran este mismo defecto y fueran capaces de realizar sus tareas de una manera tan ágil y avasalladora.

Cuando se pone a buscar sinónimos, cuando decide enjaretar un nombre o un adjetivo detrás de otro, cuando se lanza por la cuesta debajo de las enumeraciones (una acumulación retórica), entonces le salían en cascada y no había quien le hiciera parar, hasta el punto de que parece poseer un caudal inextinguible de términos, muchos de los cuales no los conocemos y hasta nos parece que se los está inventando, pero que vienen como anillo al dedo. Podríamos aportar infinidad de ejemplos, pero traeremos uno en el que hace gala de ello. De la manera que sigue califica a un presidente autonómico, cuyo comportamiento evidentemente no es de su agrado:

"Ese señor me parece / más bien un cantamañanas, un maxmordón robaperas, / un tiracantos, un maula, un adufe, un badulaque, / un bausán, un majagranzas, mamacallos, mameluco, / marmolillo y media espada. Bravo bonete sería / si vistiera de sotana, o quizá zampabodigos, / zangandongo o calabaza; si vegetal, alcornoque; / si músico, soplagaitas; si cuadúpedo, asnejón, / y si pájaro, avutarda, soplapitos, gilimursi, / gilipollas, giliflautas".

Además presume de que podría continuar sin pausa, porque sus recursos son casi ilimitados:

"Y aún podría estar diciendo / sinónimos de tontaina de aquí hasta el anochecer / o hasta pasado mañana, porque es muy rica la lengua / española o castellana...” (1994: 155). 
En segundo lugar, se observan dos tendencias muy acusadas en los artículos y columnas que ha escrito a lo largo de su vida. Una primera de carácter marcadamente literario (incluso cuando estaba tratando de cuestiones políticas), donde lo que importa es la belleza de la expresión y el atrevimiento de las imágenes y metáforas. Lo explica por el hecho de que eran los años en que la censura franquista funcionaba de una manera contundente y no era posible derivar hacia la política o la crítica, ni se podían expresar los autores con libertad, con lo cual tenían que hablar de manera que el censor no sospechara la intencionalidad de los textos (lo que se llamaba escribir entre líneas) o simplemente remontarse alto, muy alto, para no decir nada, pero, eso sí, esa nada descubrirla bellamente.

La segunda tendencia es su derivación hacia el humor. Cuando, tras la muerte de Franco, los periodistas pudieron hacer uso de la libertad de expresión y se permitió el libre juego de los partidos políticos, Campmany optó por la crítica severa de las opciones contrarias. Pero tal vez se dio cuenta de que, si entraba por esta senda, los enfrentamientos iban a ser demasiado violentos. Optó entonces, de acuerdo con su carácter plácido y amistoso, por practicar la vía del humor, que permite ser igual de contundente en los razonamientos, pero dándole una apariencia de lenidad, porque suaviza los contornos y provoca la sonrisa (y hasta es posible llegar a la carcajada). Es más fácil prevenir el enfado de los demás cuando las cosas se dicen de manera jacarandosa.

Explicaba en una ocasión cuál había sido la causa de haberse inclinado hacia esta tendencia: "Cuando empecé a escribir de política me refugié en la literatura de humor sin haberla practicado. Nunca he sido un escritor ni de ironía, ni de humor. Pero de una manera instintiva, porque tampoco me lo propuse, pensé que plantearle a la gente un drama diario criticando a los políticos o plantearle a los políticos la molestia de estar zahiriéndolos todos los días era una cosa excesiva. Entonces me refugié en la broma. A veces molesta más, pero ahí ya no tengo la culpa" (Astorga: 55). Sus seguidores disfrutaban con esta capacidad de reírse de los adversarios y estos, mientras se escocían, tenían que admitir que le sobraba ingenio.

Nos hablaba de todo ello hace algunos años7, cuando se definía como "satírico en unos momentos, pero en otros me quedo en irónico y en algunos llego a sarcástico. Al pedirme en Abc que escribiera de política, de manera instintiva me refugié en la ironía. Cuando en 1966 regresé de la corresponsalía en Roma también escribía artículos, pero el tono era más lírico y condescendiente con los políticos, como hablando a un niño. En los años posteriores la política ha tendido hacia el drama y entonces la ironía no podía ser aplicada. Ahora es otra cosa. Utilizo la ironía y la sátira porque, para una persona que escribe todos los días, es una manera de perder la seriedad. Cuando escribes un artículo diariamente no te puedes poner serio siempre

Conversación mantenida con este periodista en enero de 1995. 
ni pontificar en todos los terrenos, porque no tienes tiempo ni de enterarte bien de las cosas, así que me escapo por la vía del humor, que te permite la caricatura. No me importa exagerar, porque llamas la atención del lector y le incitas a sacar sus consecuencias". Sin embargo admite que "la sátira es con frecuencia un recurso de quien no puede cambiar la situación y se ríe de ella”. Pone el ejemplo de Quevedo, quien ocupó puestos de gran influencia, pero no le quedó más remedio que refugiarse en la sátira en algunos momentos, dada su impotencia para provocar cambios que consideraba imprescindibles.

La forma rimada, que utilizaba a veces Campmany, era parte de esa derivación hacia el humor y en ocasiones su columna no era otra cosa que un ataque al adversario, pero con la gracia y la agudeza que sabía imponer a estos versos tan asentados en la literatura española. Ya hemos explicado que los periódicos de los países hispanos siempre han estado muy abiertos a recibir y dar a conocer poesías, pero no tanto en nuestro tiempo, pues era algo más propio del siglo XIX. Ahora se trata de algo excepcional, que se reserva para aportaciones singulares de un poeta (unos versos en recuadro con ocasión de la muerte, de un premio, de una publicación fuera de lo común). Pero Campmany, sin avisar a nadie, sin colocar las palabras en series discontinuas, sorprendía al lector que iniciaba inocentemente la lectura con una rima que enseguida prendía y que aumentaba la alegría con que se realizaba aquella ${ }^{8}$. No así en la radio, donde presentaba sus versos claramente identificados como tales. Así sus dardos penetraban todavía más hondamente, y los contrarios eran objeto de risa, lo que no dejaría de dolerles más.

\section{Alfonso Ussía}

Y en cuanto al último de la somera lista que hemos elaborado, Alfonso Ussía (1948), puede vanagloriarse de pertenecer a esta corriente satírica, de hondo calado periodístico (en este campo es heredero de la habilidad versificadora de su abuelo, Pedro Muñoz Seca, además de constituirse en discípulo de Campmany). Lleva más de treinta años dedicado al columnismo, que ha ejercido en el semanario Sábado Gráfico, el los diarios Abc y La Razón y en la cadena COPE. Es el único de los citados en este trabajo que se mantiene con vida y que todavía nos obsequia con algunas muestras de su ingenio, aunque a veces sus opciones políticas un tanto extremas y sus expresiones categóricas pesen demasiado en sus exposiciones. Los versos no

\footnotetext{
8 Se podía observar esta característica en su sección “Escenas políticas” que publicaba en el diario Abc. Por ejemplo, aquí tenemos el comienzo del "Romancero de la Matilde" (fue ministra de Asuntos Sociales en un Gobierno de Felipe González): "Después de Felipe, Guerra, y después de Guerra nadie. Lo ha dicho doña Matilde, doña Matilde Fernández, que en el Gobierno es ministra de los Asuntos Sociales. Otras también lo dijeran si de esa teta mamasen, que la leche de la teta hace a los tiesos amables, a los duros hace blandos y a los hirsutos suaves. Esta ministra Matilde, doña Matilde Fernández, las públicas preferencias perfectamente se sabe, quién está en el candelero, quién del candelero sale, quién se lleva el gato al agua y quien el bacalao parte" (10-VIII-1992).
} 
son, como en muchos de los anteriores, una aportación diaria, sino más bien semanal y con frecuencia destinados a la radio, lo que constituye una singularidad, muy bien recibida por cierto.

Ussía es, al decir de Armas Marcelo, "un humorista de humo sagrado. Que no tiene por qué ser denso para ser profundo; que no tiene por qué demostrar su oficio en cada frase, aunque en cada frase se muestre un talento exuberante y sorpresivo" (Ussía, 1995: 13). Y para Campmany, "Ussía pone a caldo la corruptela, las horteradas y las mentecateces que adornan nuestro tiempo, que son muchas y que abundan por estos páramos a manta de Dios. Y lo hace con tanta inteligencia, tanta sagacidad, tanta gracia y tanta desvergüenza literaria como yo no he visto, juntas, en ninguno de mis cofrades contemporáneos” (Ussía, 1998: 21).

Nos explicaba sus planteamientos en las dos ocasiones en que tuvimos ocasión de entrevistarle: "En el articulismo satírico hay que escribir de la verdad de uno y sobre quienes están voluntariamente en puestos de poder. Yo he escrito cosas durísimas contra gente de la que soy amigo y ellos lo han comprendido perfectamente. Pero siempre tiene que subyacer ternura; nunca hay que producir heridas, sino solo arañazos" (Cantavella, 1992). Y años después: "La sátira ridiculiza y es un arma peligrosa contra los poderosos. Es un género glorioso de nuestra literatura, pero se practica menos que antes, porque hay que tener unos conocimientos, una preceptiva literaria, hay que leer mucho y saber latín y griego. Pero el problema es que ahora no se sabe escribir" (Cantavella, 1999).

Dos direcciones toman sus puyazos en las columnas que escribe: la política española y las costumbres que considera nefastas (todo ello bajo su personal criterio, claro está). Vamos a prescindir de la opinión que le merecen los gobiernos y dirigentes socialistas, los nacionalismos o el terrorismo etarra, que son temas recurrentes en sus colaboraciones, pero nos detendremos en todo aquello que le molesta en el orden social, ante lo cual desenvaina rápidamente sus versos, que pueden ser mortales si se lo propone. Igual se enfrenta a una educación "progre" que a la cocina moderna, de nombres y texturas presuntuosos (hasta en eso es conservador). Así concluye la que dedica a este último asunto, para el que demuestra especial antipatía:

"Para ellos, la porquería,

el aire de zanahoria,

el pitilín de la chirla,

el culo del berberecho

y las uñas de la hormiga.

Yo sigo con mi paella,

Mi cocido y mi tortilla" (Ussía, 2009: 95). 
También se da el caso de otros autores que, de manera menos regular, incluyen versos en sus columnas. Bastará seguir las entregas que Camilo José Cela fue publicando en el diario $A b c$, tres días a la semana si no recordamos mal. Las ofrecía siempre en prosa, pero de manera esporádica incluía versos libres, en los que prescindía de la rima, y se orientaba hacia expresiones claramente literarias, pasando por alto el soporte periodístico donde aparecían y que tienden a inclinarse sobre la actualidad, la crítica y la opinión.

Lo vemos, por ejemplo, en el poema "La traición” (17-III-1995), que constituía íntegramente la columna de ese día, que solía ser una página de huecograbado, pero dado que se distribuía irregularmente sobre el fondo de una ilustración, no ocupaba siempre el mismo espacio material (había ocasiones en que tan solo ofrecía un párrafo, mientras que en otras la escritura llenaba la página por entero). Unas semanas después ( 2 de mayo de ese año) la columna “En la muerte de un compañero pobre”, después de varios párrafos en prosa, incluye el poema “Treinta días más tarde” que comienza de esta guisa:

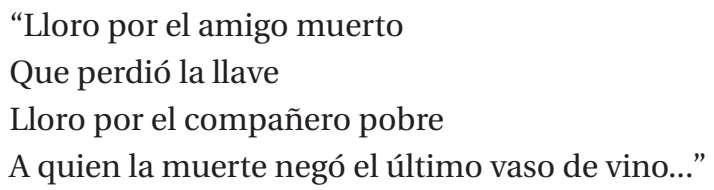

Y así hasta 23 versos, no precisamente comprensibles y atractivos para el lector medio.

Para que se vea que no solamente existen estas secciones en los periódicos españoles, basta abrir las páginas del diario limeño Perú.21 para encontrarnos con "La radiografía” de Nicolás Yerovi, donde obsequia al público con veinticuatro versos en los que comenta la actualidad, la noticia que ese día le ha llamado la atención. Por tanto, suele comenzar por dar noticia de algo que ha sucedido, pero a continuación saca sus propias conclusiones u ofrece alguna solución en línea con sus ideas.

Por ejemplo, han detenido a Juan Carlos Hurtado Miller, el otrora canciller de la dictadura fujimorista, yYerovi se muestra contento de que por fin haya dado con sus huesos en la prisión. Pero en sus últimos versos da un paso más:

\footnotetext{
“ $\mathrm{Y}$ si no lo extraditaran y si allá lo mantuvieran y en la cárcel lo dejaran y por siempre lo tuvieran? ¿No sería lo mejor y la idea más feliz?
} 
Suficiente mal olor

Padece hoy día el país".

Unas últimas apreciaciones para cerrar este artículo. Es una nota muy asentada en este tipo de aportaciones el carácter moral en el que se apoya y que desea transmitir a la ciudadanía. El horaciano "riddendo corrigit mores" se aplica aquí con toda propiedad, puesto que siempre se percibe el afán del autor por salir al paso de los defectos que observa en la sociedad y trata de poner remedio desde el humor. De forma suave se denuncia una situación y con gracia se ponen en evidencia los puntos negativos para que, sin una indicación expresa de cuál es la solución o la corrección que debe implantarse, el lector tome conciencia de lo que necesita ser reformado. Es la diferencia entre el sarcasmo hiriente, que solo causa dolor, y el aguijón templado que pretende ponernos sobreaviso respecto a todo aquello que precisa de mejora. Y de lo que se trata es de propiciar el cambio.

Por otra parte, no hay que esperar grandes resultados en el orden de la perfección formal. "Para que una poesía periodística pueda existir normalmente con la debida eficiencia periodística y poética, hay en principio una enorme dificultad”, escribió con harta razón Gerardo Diego: “Es evidente que para que la Poesía pueda hacerse periodística ha de renunciar a algunas de sus más aristocráticas excelencias y de resignarse a la levedad de un trazo menos profundo y sin ambición de indeleble perennidad" (1945: 1345). Algunos han superado esos indudables inconvenientes y se han elevado sobre la medianía, hasta dejar entrever genio e inspiración.

\section{Referencias bibliográficas}

Aguilar Piñal, F. (1981): Índice de las poesías publicadas en los periódicos españoles del siglo XVIII. Madrid: CSIC. Cuadernos bibliográficos, vol. 43 .

Alas, L. (Clarín) (2004): Obras completas (IV). Oviedo: Nobel.

Astorga, A. (2005): “Jaime Campmany: 'A mi edad me lo puedo permitir todo'”, Abc, 10-V-2005, pp. 54-55.

Bond, F. (1969): Introducción al periodismo. México: Limusa-Wiley.

Campmany, J. (1994): El libro de los romances. Prólogo de Federico Jiménez Losantos. Madrid: Espasa Calpe.

- (1995): Segundo libro de romances. Prólogo de Antonio Herrero. Madrid: Espasa Calpe.

- (1996): El jardín de las víboras. Anécdotas y epigramas desvergonzados. Madrid: Espasa Calpe.

- (1997a): Doy mi palabra. Mis 100 mejores artículos. Madrid: Espasa Calpe. 
- (1997b): El Rey en bolas y otros romances. Prólogo de Torcuato Luca de Tena. Madrid: Espasa Calpe.

Cantavella, J. (1992): “Alfonso Ussía: ‘El fútbol se ha convertido en una guerra en la que se llega a matar’”, Hoy (Badajoz), 28-VI-1992, p. 35.

- (1999): “Alfonso Ussía: 'Prefiero comer con un tonto que con un político’”, Diario de Burgos, 19-VI-1999, p. 7.

Diego, G. (1945): “Periodismo y poesía”, Gaceta de la Prensa Española, n. o 34, Madrid, 1-III-1945, pp. 1345-1346.

Espina, A. (1960): El cuarto poder. Cien años de periodismo español. Madrid: Aguilar.

Flor, José Luis R. de la (1993): Un siglo de poesía satírico-burlesca periodística (1832-1932). Madrid: Ediciones de la Torre.

Gómez Aparicio, P. (1967-1981): Historia del periodismo español (4 vols.). Madrid: Editora Nacional.

González (Ansúrez), F. A. (1993): Ripios. Valladolid: Ayuntamiento de Valladolid.

Gordillo Courcières, J. L. (1994): Un poeta satírico del XIX. Los sonetos políticos de Manuel del Palacio. Madrid: Compañía Literaria.

Granés, S. M. (1880): Calabazas y cabezas. Semblanzas de personajes, personas y personillas que figuran o quieren figurar en política, literatura, armas, ciencias o tauromaquia, escritas en verso por... e ilustradas por caricaturas de Perea y Luque, con una carta-prólogo de Manuel del Palacio. Madrid: M. Romero impresor, 2. a edición.

Haro Tecglen, E. (1996): “El ripio y Luís de Tapia”, Babelia, El País, 23-III-1996, p. 14.

Hernando, Bernardino M. (2007): La corona de laurel. Periodistas en la Real Academia Española. Madrid: APM.

Herrera Cerezo, D. (2010): “Los recursos humorísticos en las columnas de Alfonso Ussía sobre la política vasca”, Doxa Comunicación, n. ${ }^{\circ} 11$, pp. 141-159.

Jiménez Losantos, F. (1994): El libro de los romances. Madrid: Espasa Calpe.

Llanos, M. (1982): Raimundo de los Reyes, poeta y periodista. Murcia.

Marquina, E. (1910): Canciones del momento. Odas de la ciudad y horas trágicas. Prólogo de Enrique Gómez Carrillo. Madrid: Francisco Beltrán.

Ossorio y Bernard, M. (2004): Ensayo de un catálogo de periodistas españoles del siglo XIX. Madrid: Hemeroteca Municipal (edición facsímil de la de 1904).

Palacio, M. del (1894): Chispas. Madrid: Sucesores de Rivadeneyra.

Palomero, A.: Coplas de ‘Gil Parrado. Madrid: Librería de Fernando Fe.

Reyes, R. de los (1958): Ripios del día de Luis Romera. Prólogo de Federico Carlos Sainz de Robles. Madrid.

Río Sáinz, J. (1922): La belleza y el dolor de la guerra. Versos de un neutral. Valladolid: Imprenta de la Viuda de Montero. 
Sanmartí, J. M. (2007): “La columna, el género más personal”, en: Cantavella, J. y Serrano, J. F.: Redacción para periodistas: opinar y argumentar. Madrid: Universitas, pp. 193-216.

Sans, E. (2009): “Félix Antonio González, poeta, pintor y periodista”, El País, 6-X-2009, p. 44.

Tapia, L. de (1911): Bombones y caramelos. Prólogo de Benito Pérez Galdós. Madrid: Establecimiento tipográfico de $E l$ Liberal.

- (1917): Coplas del año. Madrid: Renacimiento.

Ussía, A. (1995): Pasajes de la vida. Prólogo de J. J. Armas Marcelo. Madrid: Espasa Calpe.

- (1998): Versos prohibidos. Prólogo de Jaime Campmany. Madrid: Espasa Calpe.

- (2009): Sopas bobas y pesebres. Versos satíricos de la España de hoy. Madrid: Temas de Hoy.

Varillas Montenegro, A. (2008): El periodismo en la historia del Perú. Desde sus orígenes hasta 1850. Lima: Universidad de San Martín de Porres.

Zavala, Iris M. (1972): Románticos y socialistas. Prensa española del XIX. Madrid: Siglo XXI de España Editores. 